\title{
Polyester resin injection of dynamic resin and cable bolting systems to improve development efficiency
}

\author{
T Roberts Jennmar Australia Pty Ltd, Australia \\ D Faulkner Jennmar Corporation, USA
}

\begin{abstract}
Traditional mechanised resin rockbolting in hard rock underground mines requires the installation of resin capsules into a pre-drilled hole, prior to the rockbolt being spun into a hole to mix the resin and set the bolt in place. In poor rock mass conditions, especially at depth or in highly altered faults and shears, the condition of the holes often deteriorates, as the poor ground around it unravels and falls into the hole. This results in partially or fully blocked holes, that either damages the resin capsule when they are being inserted into the hole, or prevents the resin capsule from being inserted until the hole is entirely cleaned of debris. This deterioration of the hole condition, and continuous need to clean and re-drill holes, also increases the diameter of the hole which in turn affects the continuously mechanically coupled anchorage mechanism of the rockbolt to the rock mass as there is simply not enough resin in the hole to fill the annulus between the bolt and the rock. This results in a large increase to critical heading cycle time and, more importantly, results in the rock reinforcement not performing as per design specification and increases the risk of instability. To overcome the quality control issues with resin bolt installation in poor ground, a single pass drill, install, inject and tension self-drilling resin bolt application was designed and implemented for use in such conditions. This system allows the operator to inject a two-part polyester resin through a self-drilled hollow bolt to mix and fully encapsulate the rock reinforcement. The self-drilling bolt allows for post-injection of the hole after the bolt has been installed into the rock and gives the operator manual or automated control on the amount of resin used to fill the hole, ensuring complete encapsulation and continuously mechanically coupled anchorage to the rock. This allows the reinforcement to work as designed and provide the geotechnical engineer extra quality control confidence in these conditions. The implementation of this single pass resin-bolting system resulted in significant decreases to the resin-bolting cycle time and rockbolt quality control failures. In this paper the design, implementation and embedment into the development cycle will be discussed and the in situ quality control checks used to validate the increase in rockbolt installation quality will be shared.
\end{abstract}

Keywords: rapid development, quality control, ground support, poor ground, self-drilling resin bolt, geotechnical engineering

\section{Introduction}

In underground mining, any unstable rock in mine openings may result in personnel injury/fatality, equipment damage, and production interruption. To stabilise the excavated opening, the rock mass is typically supported immediately after excavation by installing rockbolts that are either mechanically/friction anchored, or grouted using resin cartridges. Over the last several decades, the resin-assisted rockbolting system has gained wide acceptance in the mining and civil industry due to its quick setting time, reliable anchorage, low cost, and other outstanding features such as durability, corrosion protection, shear resistance, and sealing of fractures. However, insertion of a polyester resin cartridge tends to be difficult in poor ground, high openings and/or for long tendon installation. Some operators pneumatically shoot polyester resin cartridges into bolt holes, but broken ground, collapsed drill holes and irregularly shaped holes can burst a standard cartridge when fired into drill holes. To date, the method of installing resin capsules using a polymer tube and adaptor mounted to a jumbo drill is most common. Using the drill boom, insertion of the resin capsule is completed with a cap/parachute attached to fix the capsule. The boom is 
then withdrawn along with the polymer tube from the drillhole, leaving the resin capsule installed into the drillhole. This method of installation is susceptible to the same issues encountered when shooting resin capsules, where the polymer tube has difficulty being inserted into the drillhole in poor ground and collapsed drill holes, generally breaking or damaging the polymer tubes and resin capsule/cap assembly.

Traditional resin-bolting techniques rely on good drillhole integrity for satisfactory installation of resin bolts. In poor rock mass conditions, traditional resin-bolting methods are often a lengthy and frustrating process for ground support installation operators and often results in a low pass rate for quality control (QC) assessments, such as bolt pull testing and over-coring. To overcome these difficulties, installation of rockbolts with a pumpable resin system became necessary. In last a few years, various pumpable resin systems have been in the development process by various companies, all using a two-part urea-silicate resin.

From a material engineering perspective, both the polyester and urea-silicate resin have pros and cons, and hence their engineering applications should be different per given geotechnical conditions, although there are very few technical publications addressing the differences of both resin products. Some misunderstandings exist in industry, such as urea-silicate resins will perform in a similar way as polyester resins, urea-silicate resins are better, urea-silicate resins are comparable to polyester resins in cost, and so on.

Polyester resins are the most widely used resin systems in various industries due to material availability, easy usage, low cost, and excellent material properties. The operating service temperatures for polyester resins are wider than other resin systems. Polyester resins are versatile because of their capacity to be modified or tailored during the manufacturing of the polymer chains. The principal advantage of the polyester resins is a balance of properties (including mechanical, chemical, and electrical), stability, safe to use, cost effective, has high mechanical strength and ease of handling for transport and use underground. For these reasons, the J-Lok P system discussed has been designed to utilise polyester resin (Stankus \& Ma 2018).

This paper details the development of a polyester resin injection system for various rock and cable bolting applications, dynamic support elements to support resin injection processes and comparisons and performance of polyester resins in terms of material properties and application.

\section{Traditional resin-bolting techniques}

The resin bolt installation process works very well in most rock mass conditions. In poor rock mass conditions there are many challenges with this technique and it often results in very poor installation quality, if they can be installed at all. It also leads to excessive frustration levels for the operators who are attempting to install the rockbolts. This frustration has been observed to, on occasion, lead to taking shortcuts or differing from standard practice to get the bolt in as best as possible. This practice results in the installation of cosmetic support that is visually there, but not working to its designed parameters.

It has been observed at many mining operations, that when these conditions are encountered the following conditions are observed:

- Drillhole collapse or blocking from small blocks falling into the hole.

- This results in often excessive amount of re-drilling in an attempt to clean the hole.

- Drillhole diameter increase.

- This results from crumbling of the rock around the drillhole increasing its diameter.

- Over drilling of the hole length.

- Due to running the steel up and down the hole to clear it so often the length is unknowingly increased.

- Poor operator quality control not marking drill steels to required drill depth. 
All of the aforementioned conditions that arise when drilling a hole in poor rock mass, lead to inadequate installation of the internal reinforcement and can result in the following:

- Poor encapsulation of the resin bolt.

- From oversized or excessively long holes.

- Inadequate mixing of the resin mastic and catalyst.

- In oversized holes the rockbolt can run alongside the resin capsules and not break the capsule skin adequately and poorly mixing the resin mastic and catalyst together.

- Potential gloving of the bolt.

- During installation, especially in larger holes caused from soft rock or poor ground conditions, the capsule increases in diameter when pushed against and can lead to the bolt piercing the front of the resin capsule the capsule film wrapping around or covering the bolt, reducing resin contact between the bolt and rock.

As a result of poor quality drill holes and ultimately inadequate installation of the resin bolt, the capacity is either significantly reduced, or does not function at all as per parameters specified in the design documents, examples of such drill holes can be seen in Figure 1 . This results in a significant stability risk to the excavation and the safety of miners.

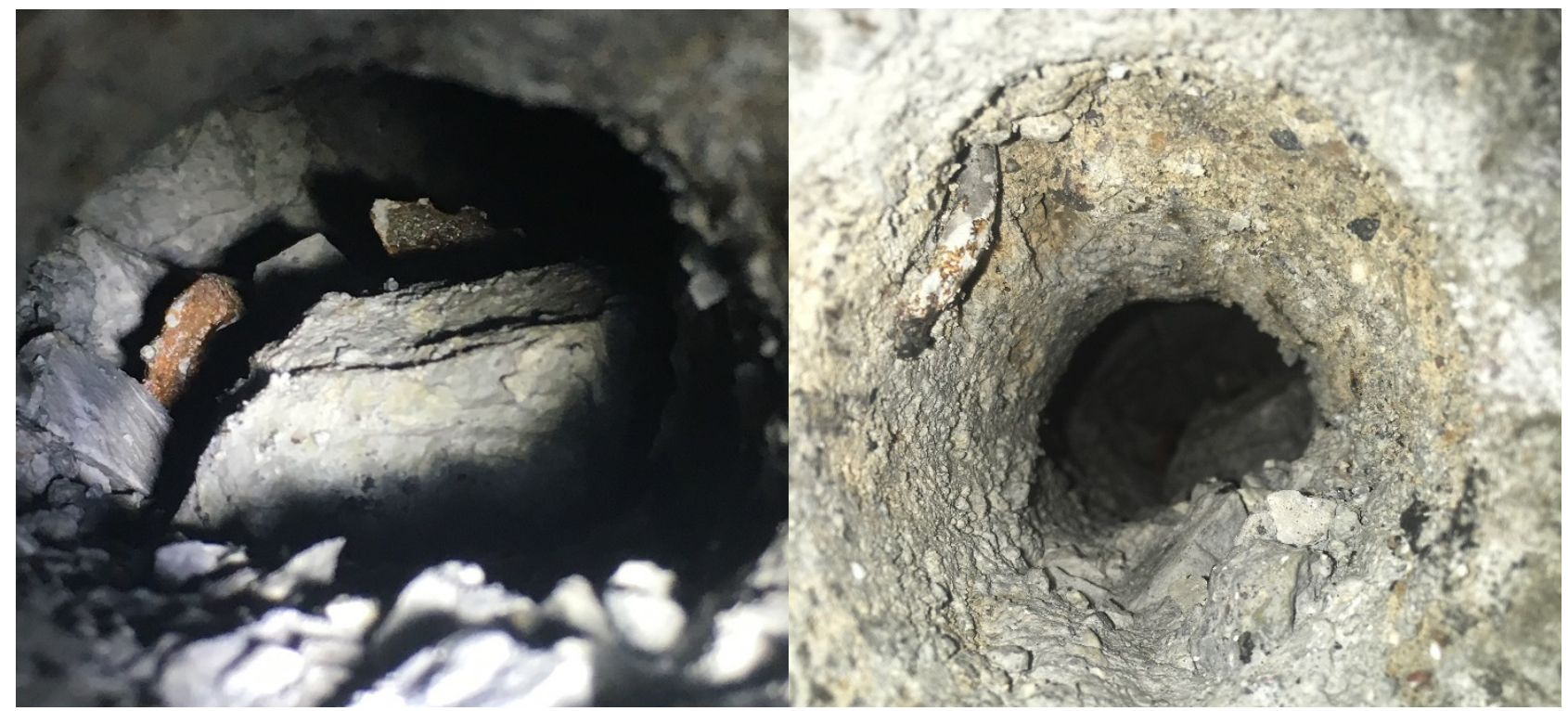

Figure 1 Typical hole conditions where the J-Lok P system is to be utilised, showing collapsed and 'blown out' drill holes. These are the type of ground conditions where traditional resin-bolting is extremely difficult and time consuming

\section{The J-Lok $P$ system}

The J-Lok $\mathrm{P}$ system is a specialised automated controlled pumping system. It comprises of two main components, a loading station and injection module. The loading station uses two loading cylinders with manual hatches to easily transfer resin and catalyst from ground level into the injection module, while keeping the product free from debris and containments as shown in Figure 2. The injection module shown in Figure 3 consists of two high pressure 100 litre (total volume) bulk pumps that can maintain a consistent specified pumping ratio of the two-component resin. The injection module is operated manually or automatically from the safety of the machines cab. The system is completely sealed and material kept separated until the injection point, requiring minimal clean-up at the end of shift. If maintenance is required, the system is designed to be easily repairable. 


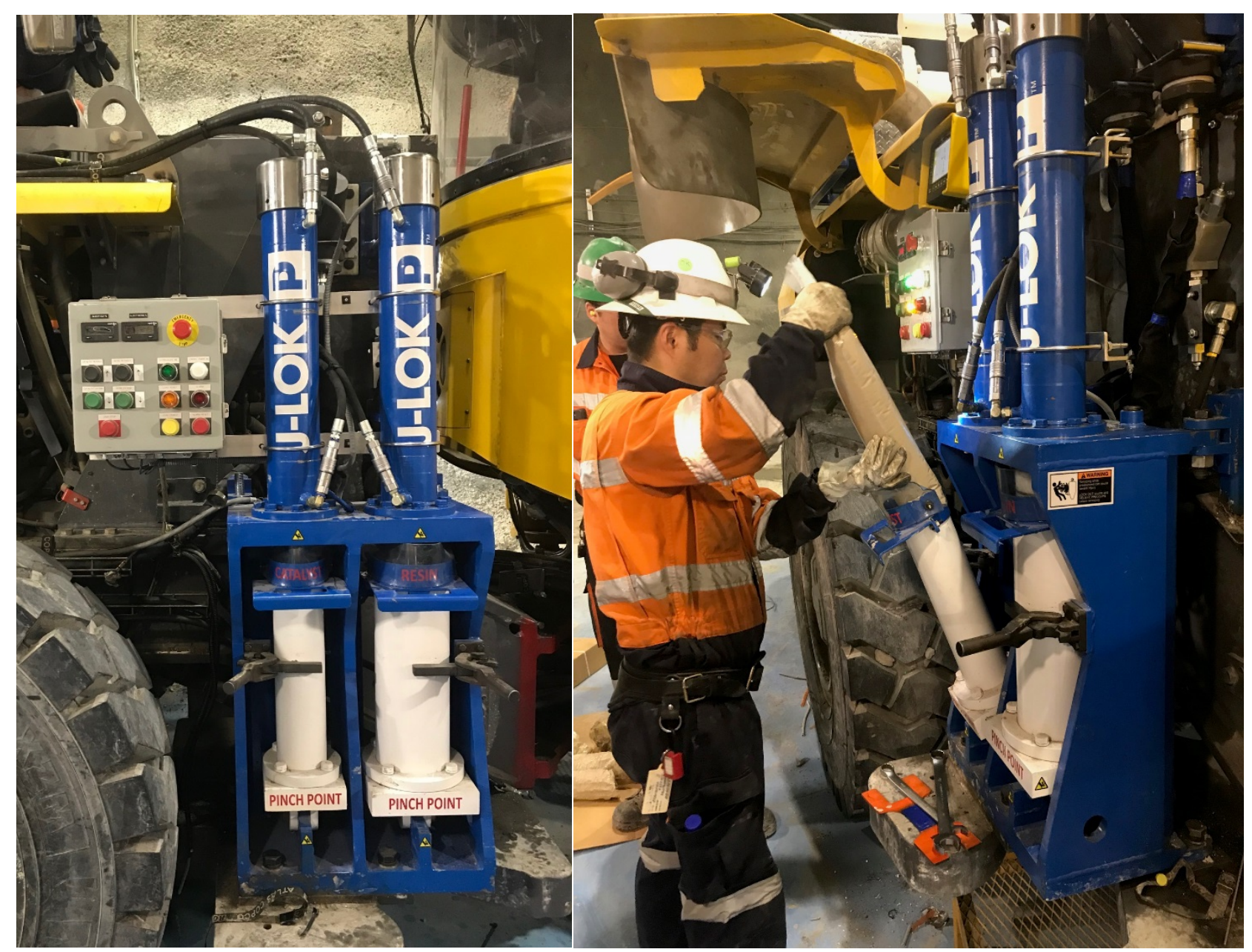

Figure 2 J-Lok $P$ resin loading cylinders and catalyst (smaller $7 \mathrm{~kg}$ white bag) being loaded into injection tube

The J-Lok P system is supplied as a 'bolt-on' assembly to rockbolting equipment as shown in Figure 3 or supplied as a skid mounted unit as shown in Figure 3. The J-Lok P system utilises on-board hydraulic and 24 volt power supply and system specific programmable logic controller (PLC) for system operation when mounted directly onto a bolting, cable bolting or jumbo drilling machine. Skid mounted systems utilise mine power to connect directly into 600 volt or 1,000 volt receptacles. 

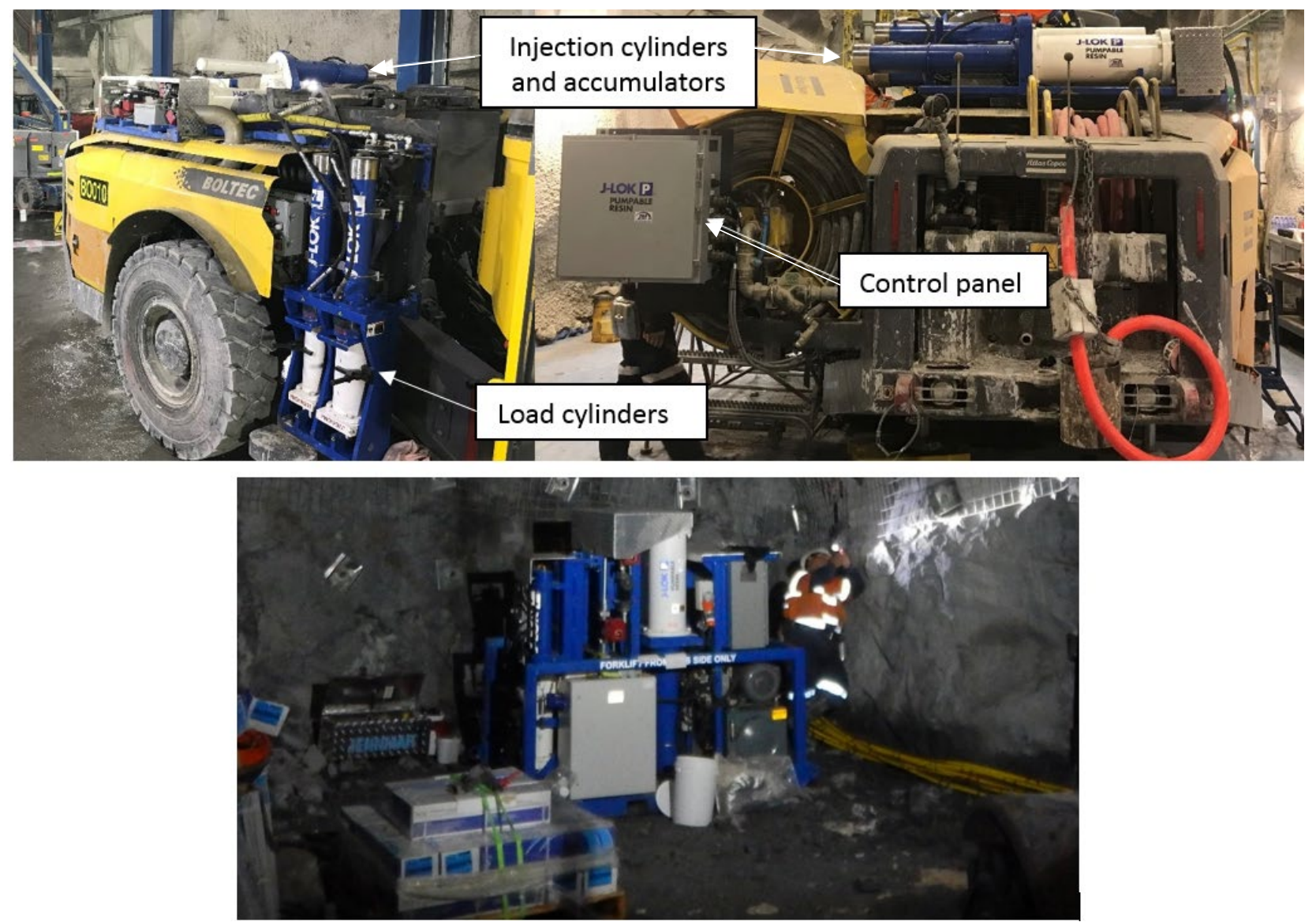

Figure 3 J-Lok P installation onto Boltec drill. Resin and catalyst load cylinders are mounted on the side of the Boltec and injection cylinders and 100 litre accumulators are mounted on the top of the Boltec. A J-Lok P skid mounted resin injection system being utilised for cable bolting applications and connected to 1,000 volt jumbo starter power supply

Injected resin and catalyst are pumped through steel reinforced hoses which are connected to the injection head assembly. The injection head assembly is attached to a hydraulic cylinder, when pushed onto the end of the installed bolt, sealing the nylon injection nozzle against the end surface of the bolt, allowing the resin and catalyst to be injected into the bolt.

\subsection{J-Lok $P$ polyester resin and catalyst}

Polyester resin is used with the J-Lok $\mathrm{P}$ system due to its cheaper material costs when compared to polyurethane resin (PUR) and urea-silica resin (USR), higher strength, easy handling and storage requirements and safe usage, as urea silicates become volatile during transportation and storage on remote mine sites. Urea silicates also have a short shelf life and are susceptible to extreme temperature changes. Without total control over the supply chain, it is the authors' experience that two-component PUR and USR resins are significantly harder to ensure consistent and reliable quality of products when they arrive on site. This is exaggerated by extreme weather and remote locations of many mining operations. Even when on site in the storage facilities, urea-silicate is often required to be agitated significantly to correct segregation and crystallisation of the components. Due to these significant reasons, polyester resin was selected to be used with the J-Lok P system.

J-Lok $\mathrm{P}$ is packaged in 41 pound $(18 \mathrm{~kg}$ ) resin (mastic) and catalyst kits, with 52 kits per pallet $(2,160 \mathrm{lbs} / 980 \mathrm{~kg})$, which allow for easy handling of the material. The resin and catalyst are transferred into the injection accumulators by use of load cylinders. Five resin kits are used to fill the resin injection accumulators and 20 bolts or three $6 \mathrm{~m}$ cable bolt holes can be installed using the accumulator resin storage. 
It must be noted that additional resin kits can be loaded at any time into the injection accumulators during the bolting cycle.

A distinct advantage from cartridge resin is that plastic is not pumped into the system, ensuring there is no resin bond interference between the bolt and rock, maximising contact shear strength. The on-board display inside the cab as seen in Figure 4, allows the operator to monitor all functions of the J-Lok P system. The packaging is removed during this process allowing for minimal waste as shown in Figure 5. Simple operation and monitoring features allow users to quickly understand and manage system functions. The current load function selected shows resin half way through a loading process. As resin is loaded, the volume in the injection accumulators increases until it reaches full capacity. The shot size in the bottom left corner, displays the volume entered by the operator and when automatic injection is selected, a screen displays a linear gauge, showing the shot size being injected. Should the shot size not be sufficient due to ground conditions or increased hole size after drilling, manual injection can be selected until resin can be seen pumping from the hole or surrounds the bolt plate. Visually seeing resin pumping out of the hole, verifies to the operator that the bolt is fully encapsulated.

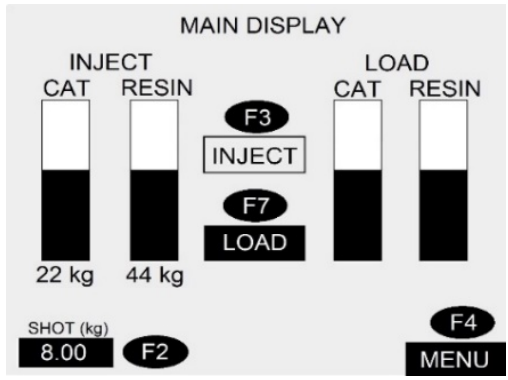

Figure 4 Cab mounted PLC display which shows resin being loaded and the available resin volume ready for injection

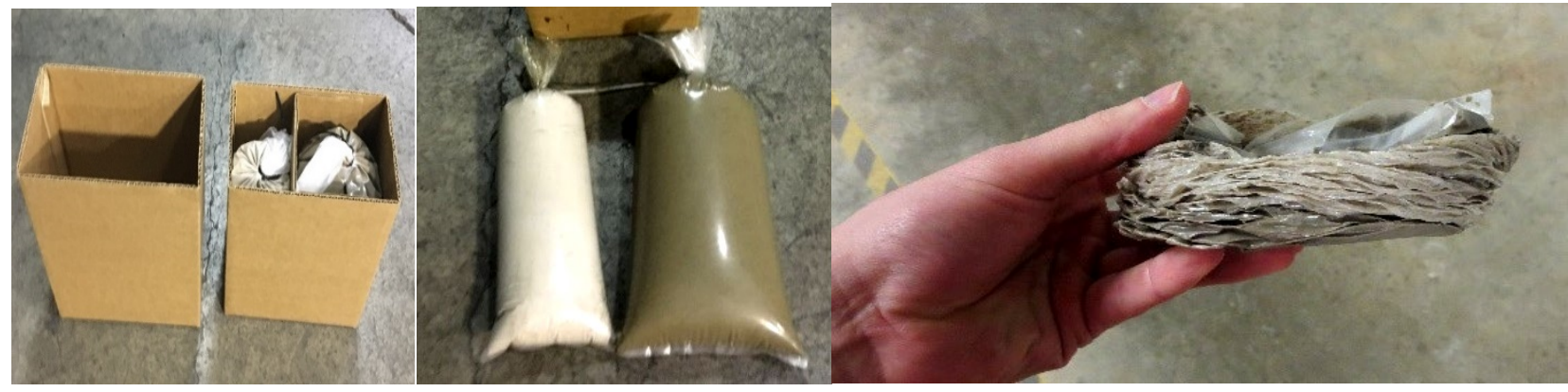

Figure 5 Resin shown in 2:1 catalyst/resin mix ratio and bag shown after resin injection. $18 \mathrm{~kg}$ resin/catalyst are in each $600 \mathrm{~mm}$ long boxes, easy transported to varying locations for use

Due to the resin being housed in a sealed system, resin can remain sealed inside the resin grout lines and injection accumulators for greater than six months, without being effected by varying temperature and conditions. This is beneficial if the drilling machine breaks down for a long period of time, knowing the resin is ready to use for bolting once repaired. Being a water based resin, the system design is clean producing minimal waste or resin loss.

\section{$3.2 \quad$ J-Lok P rockbolt Installation}

The use of a single pass drill, install and inject self-drilling anchor (SDA) significantly decreases the installation time of rockbolts in poor ground when compared to traditional resin-bolting methods. Use of the J-Lok $P$ system also delivers the following benefits:

- Continuously cleaning holes for resin cartridge insertion no longer required.

- Blocked holes for resin cartridge insertion is no longer an issue. 
- The resin volume required as a function of final hole diameter in poor ground, is not restricted by the cartridge volume, it can be pumped as required to fill the hole.

- Resin is mixed as it enters the SDA and the mixed product is pumped into the hole through the SDA static mixer and drill bit ensuring adequate mixing.

- Resin set time is customisable to suite rock temperature, pump speeds and varying bolt lengths.

- Drilling, installation, plate and tensioning of the nut and plate is done from the cab of the bolting equipment, no exposure to operators near unsupported ground.

- No longer a two-pass option requiring multiple machines and operators to inject the bolts separately and then plate and tension after curing.

Critical for successful installation are correctly designed tools, software programming for system integration and sequencing of both the drilling machine and J-Lok $P$ resin injection process. This allows for successful bolt installations when utilising trained and skilled operators. A typical SDA rockbolt installation using a Boltec drill is shown in Figure 6. Figure $6 a$ shows loading of the catalyst, Figure $6 \mathrm{~b}$ shows drilling the bolt into the rock wall, Figure $6 \mathrm{c}$ shows injection of J-Lok $\mathrm{P}$ resin into the installed rockbolt and Figure $6 \mathrm{~d}$ shows tensioning of the rockbolt (Watt et al. 2018). This process is completed without needing to move the boom of the drill.
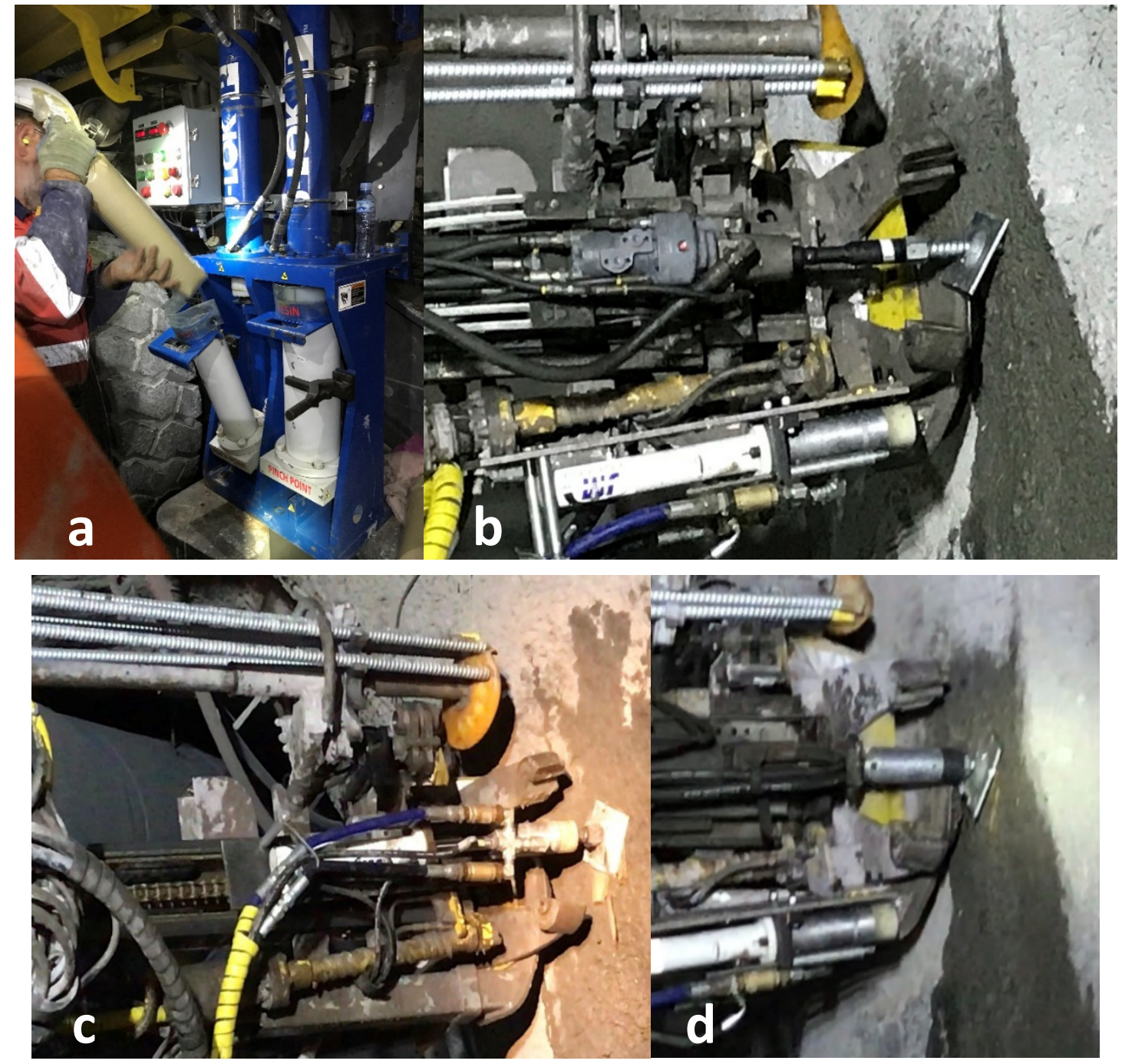

Figure 6 Installation sequence showing resin loading and drilling with the SDA. Installation sequence showing rolling/indexing the injection head assembly into position and injecting the bolt and hole with the two-part polyester resin and tensioning of the bolt. All processes shown in Figure 6 are completed in a single installation pass 


\subsection{J-Lok P self-drilling bolt selection}

The R32 SDA is a commonly used bolt, predominantly used in civil spiling applications and side walls of mines, where collapsing holes make it difficult to install standard resin-bolting type products. The R32 SDA bolt is stiff system when fully encapsulated, therefore only used where geotechnical domains require static application. To overcome the stiff self-drilling bolting element, a product named a multiple point anchor (MPA) bolt was developed.

The patent pending MPA bolt is supplied with a $43^{\prime \prime}(1,000 \mathrm{~mm})$ threaded bolt toe and $12^{\prime \prime}(300 \mathrm{~mm})$ threaded section for nut tensioning. The nuts are pinned leaving a $60 \mathrm{~mm}$ tail to allow for bolt installation and resin injection. Bolt lengths supplied are $2.4 \mathrm{~m} / 94^{\prime \prime}$ and $3.0 \mathrm{~m} / 118^{\prime \prime}$, but any desired length can be utilised for spiling or larger excavations needing longer support elements, or coupled for longer bolt lengths. An MPA bolt example is shown in Figure 7.

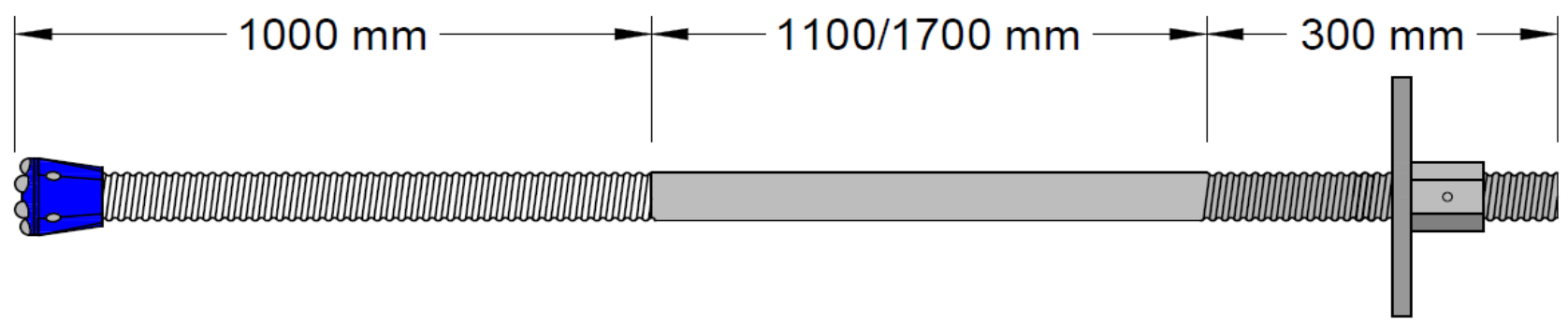

Figure 7 MPA bolt suitable for operations with squeezing ground or dynamic geotechnical domains. The $3.0 \mathrm{~m}\left(118^{\prime \prime}\right)$ bolt has a longer annealed section

The centre of the MPA bolt has no thread rolled into the bar (round bar), which prevents the bolt from bonding to the resin. This smooth section of bolt is annealed, which increases the elongation capacity of the bolt significantly (Faulkner et al. 2017). Detail of the bolt strength in the threaded and annealed sections of the bolt are shown in Figure 8. The annealing process is shown in Figure 9.

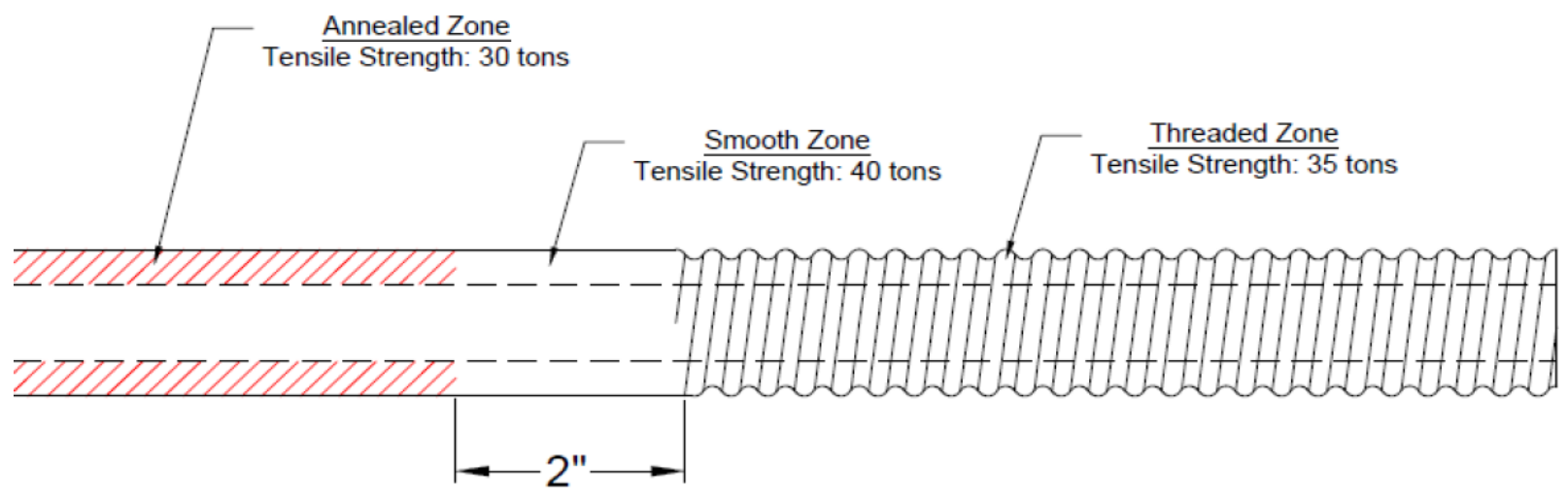

Figure 8 Bolt capacity (imperial measurements) shown in the various sections of the bar

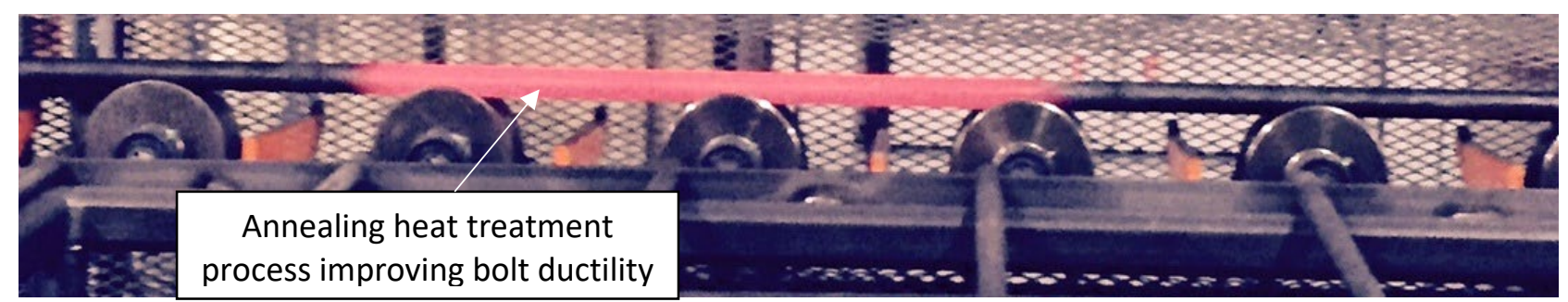

Figure 9 Annealing of the MPA bolt and finished bolts strapped after manufacturing 
Annealing is a heat treatment that alters the physical and sometimes chemical properties of a material to increase its ductility and reduce its hardness, thus improving the bolts elongation capacity for improved application in quazi-static and dynamic conditions. Bolt specifications are shown in Table 1.

Table 1 MPA bolt technical specifications

\begin{tabular}{llllll}
\hline Description & \multicolumn{2}{l}{$\begin{array}{l}\text { R32 MPA bar } \\
\text { annealed section }\end{array}$} & $\begin{array}{l}\text { R32 MPA bar } \\
\text { thread section }\end{array}$ & $\begin{array}{l}\text { General } \\
\text { data }\end{array}$ \\
\hline & & kN & & kN & \\
\hline Yield strength of steel & Typ & 220 & Typ & 250 & - \\
Tensile strength of steel & Typ & 270 & Typ & 320 & - \\
StandardeElongation & Min & $20 \%$ & Min & $10 \%$ & - \\
Shear strength $(0.7 \times$ UTS) & - & 190 & - & 224 & - \\
Bar diameter $(\mathrm{mm})$ & Core & 27.5 & Major & 31.5 & - \\
Cross-sectional area $\left(\mathrm{mm}{ }^{2}\right)$ & - & - & - & - & 430 \\
Mass per metre $(\mathrm{kg} / \mathrm{m})$ & - & - & - & - & 3.4 \\
Recommended drill bit size & - & - & - & - & 42 \\
\hline
\end{tabular}

In order to better understand the capabilities of the MPA bolt, dynamic testing of the bolt using J-Lok P injected resin is currently being carried out at the Western Australian School of Mines (WASM).

\section{$3.4 \quad J-L o k$ P cable bolt selection}

Utilising the J-Lok P system for cable bolting application provides significant development efficiency advantages over traditional cable bolt installations by eliminating the 'waiting time' for grout to cure. Conducting cable bolt installations using J-Lok P resin is completed using a cable bolting machine or hand installed using traditional techniques. When completing cable bolt installations underground, multiple cable bolts can be installed and pumped with J-Lok P resin immediately allowing cables to be tensioned to $10 \mathrm{t}$ in 20 minutes. As shown in Figure 10, J-Lok P resin injected cable bolt installations are installed using traditional cable bolting techniques.

Similar to rockbolting, dynamic cables were developed to provide options for engineers focusing on resin injection in dynamic geotechnical domains. Two dynamic cable bolt products providing differing results due to varying construction methods, mechanical properties and material grade were developed in conjunction with the J-Lok P system. Named GRACOM and SECTA cables, both cables are supplied as cable reels to mount onto cable bolting machines or supplied as pre-cut cables to be used with the J-Lok P resin injection system.

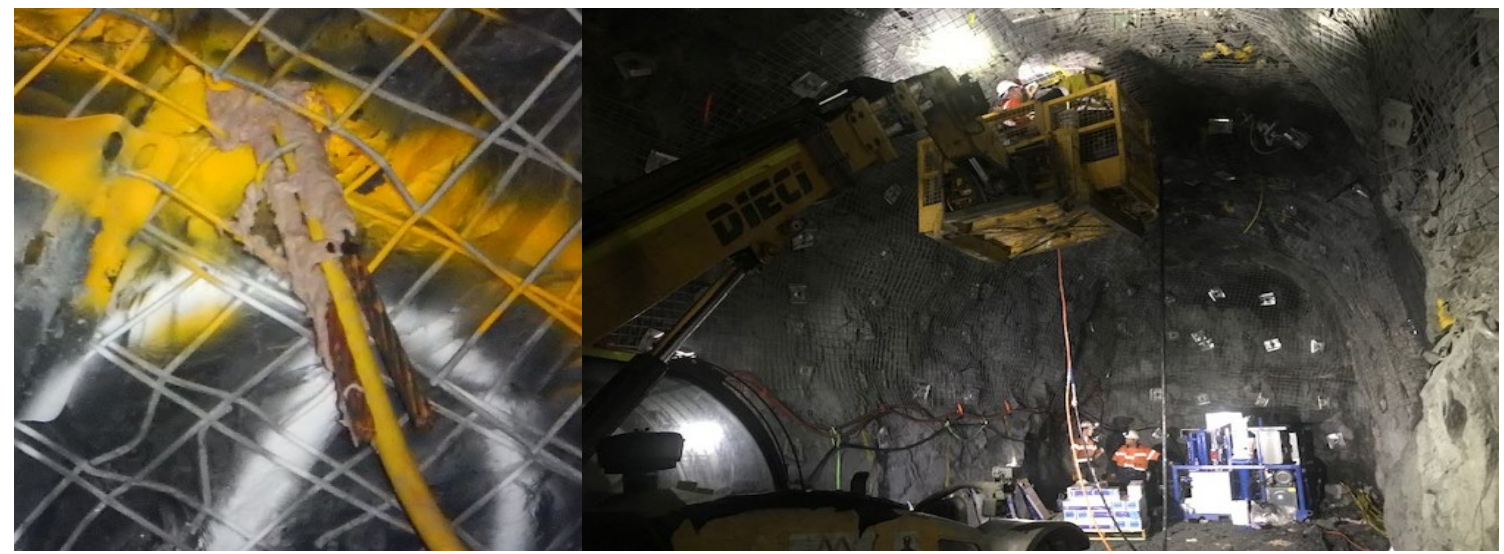

Figure 10 SECTA cable installed using traditional installation methods and J-Lok $\mathrm{P}$ resin 
The GRACOM (grade composition) cable is a $17.8 \mathrm{~mm}$ grade composite cable, utilising ultra-low yield internal wires and ultra-high strength external wires. The ultra-low yield steel wires are designed to provide longitudinal deformation, maintaining energy dissipation capacity. Warping deformation is restricted by external ultra-high tensile wires. The grade composition of wires is shown in Figure 11. When the cable is confined with a full resin grout column, strand warping is further controlled. The ultra-high tensile wires are required to absorb the event initial load, whilst the ultra-low yield steel wires absorb higher energy through displacement. When the cables are tensioned with a yield tube and domed barrel and wedge assembly, a higher energy absorption is achieved. Tables 2 and 3 provide technical specifications of both GRACOM and SECTA cables.

Table 2 GRACOM cable bolt technical specifications

\begin{tabular}{llllll}
\hline Description & \multicolumn{2}{c}{ GRACOM cable } & GRACOM cable & General data \\
\hline & & kN & \multicolumn{3}{c}{ Tonnes } \\
\hline Tensile strength typical value & Typ & $>364$ & Typ & $>37$ & - \\
Tensile strength actual value & Typ & 371 & Typ & 37.9 & - \\
Typical elongation & Min & $>5 \%$ & - & - & - \\
Actual elongation & Min & $7.8 \%$ & - & - & - \\
Cable diameter $(\mathrm{mm})$ & Major & 17.8 & Major & 18.0 & - \\
Mass per metre $(\mathrm{kg} / \mathrm{m})$ & - & - & - & - & 1.62 \\
\hline
\end{tabular}

Table 3 SECTA cable bolt technical specifications

\begin{tabular}{llllll}
\hline Description & \multicolumn{2}{l}{ SECTA cable } & \multicolumn{2}{c}{ SECTA cable } & General data \\
\hline & & kN & & kN & \\
\hline Yield strength of steel & Typ & 280 & Typ & 330 & - \\
Tensile strength of steel & Typ & 350 & Typ & 370 & - \\
Standard elongation & Min & $3.5 \%$ & Min & $6 \%$ & - \\
Cross-sectional area $\left(\mathrm{mm}^{2}\right)$ & - & - & - & - & 209 \\
Mass per metre $(\mathrm{kg} / \mathrm{m})$ & - & - & - & - & 1.65 \\
\hline
\end{tabular}

GRACOM : Graded Composite Hybrid Strand

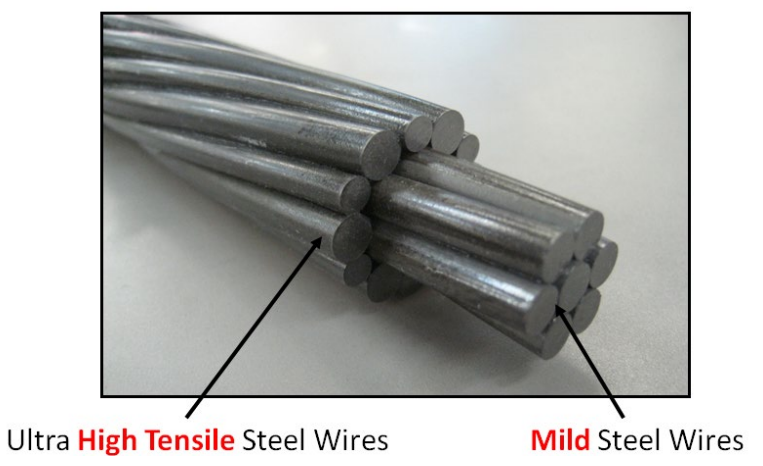

Figure 11 The GRACOM cable showing both ultra-high and ultra-low grade composite stand construction

Dynamic testing completed by WASM outlines results regarding dynamic laboratory testing of fully coupled cement-encapsulated single strand GRACOM and SECTA cable bolts as shown in Figure 12. Further testing is planned at WASM using J-Lok P resin. 


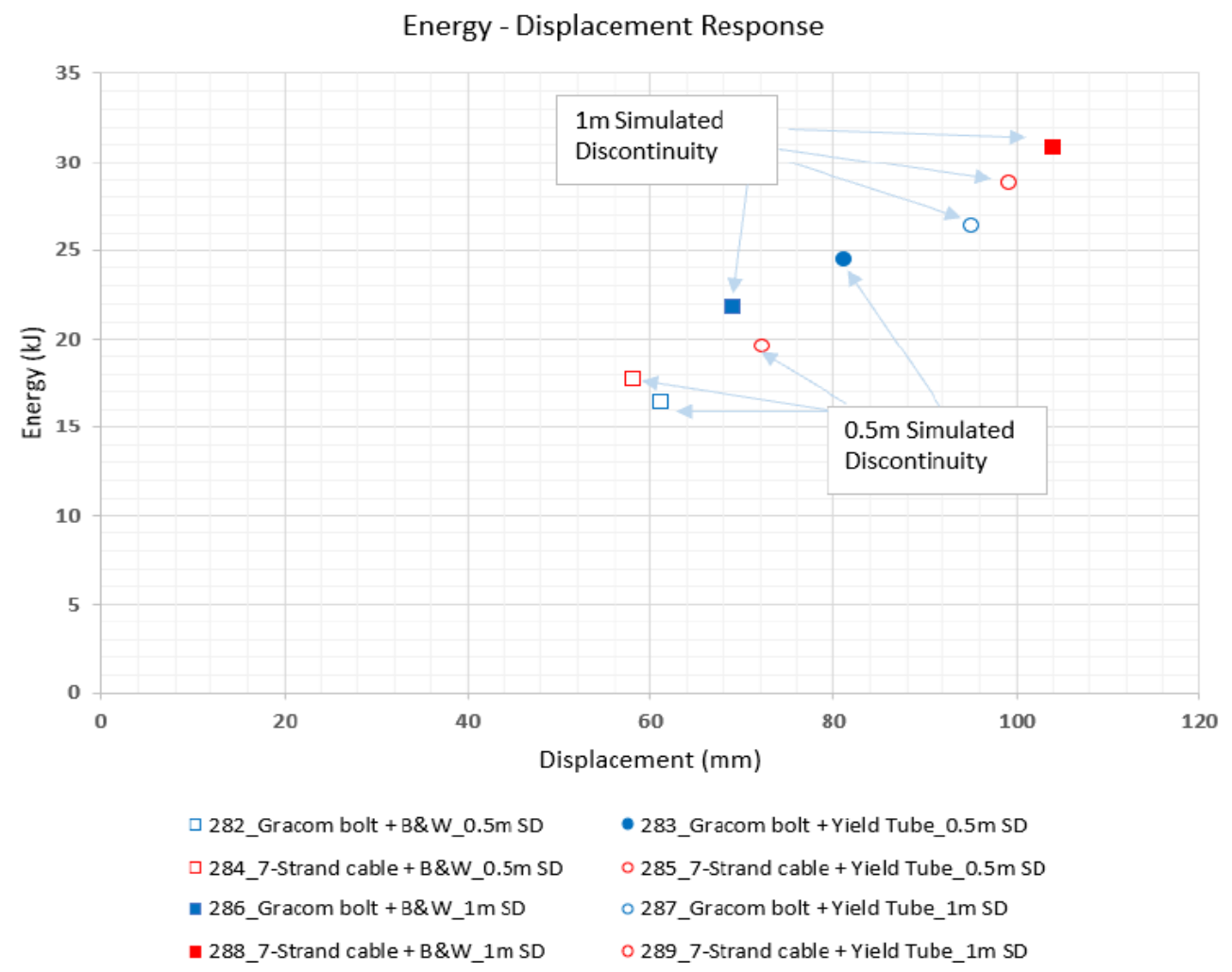

Figure 12 Dissipated energy of GRACOM and SECTA cables tested at WASM

The dynamic test arrangement involved drilling a three metre grouted steel tube with a 50 NB drill bit. Cables were grouted into the boreholes using a 0.4 water/cement grout ratio. After a 28 day grout curing time, the cables are tensioned to $8 \mathrm{t}$ using a mix of barrel and wedges, and yield tube barrel and Wedge assemblies as shown in Figure 13, sourced from WASM dynamic testing reports (De Zoysa \& Manoj 2018). Each bolt uses a $200 \times 200 \times 14 \mathrm{~mm}$ volcano plate.
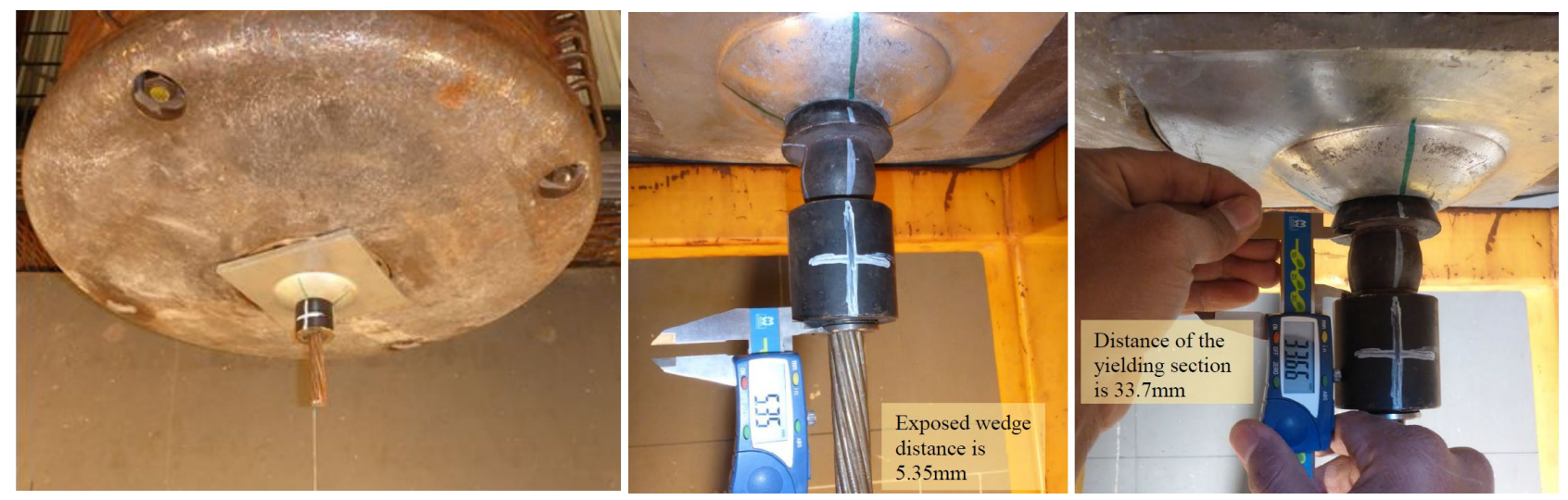

Figure 13 Post-testing SECTA cable with barrel and wedge, and prior test GRACOM cable with yield tube and barrel and wedge arrangement (De Zoysa \& Manoj 2018)

For each cable type tested, the energy dissipation at the collar is aided by load transfer due to high-quality grouted-cable encapsulation. The range of stable dissipation energies measured at the collar are 18-20 kJ. The energy dissipation for each GRACOM and SECTA cable strand (deeper failures) ranged from 26-29 kJ. 


\section{$4 \quad$ J-Lok $P$ performance}

The main objective of the J-Lok P system is to evaluate efficiencies and improvements for the following:

- Ground support element design to economically mitigate the risk, with minimal future unplanned repair/rehabilitation.

- Improve development efficiency in poor ground.

- Industry best practice and innovative solution.

- Fit for purpose products should meet life-of-mine (LOM) and design requirements.

- System easy to operate and support, provided by ongoing training, monitoring and in-country spare part and ground support supply.

The average installation time to completely self-drill, inject and tension a bolt using the J-Lok P system varies depending on operator experience, whether a machine offsider/operator is present and system being used. Using a Boltec machine, installations can be completed in 3 minutes and 45 seconds using a $2.4 \mathrm{~m}$ bolt and $6 \mathrm{~m}$ cable bolt can be installed, pumped, and tensioned to $10 \mathrm{t}$ in 20 minutes.

Irrespective of ground conditions, the time for installation does not differ due to the installation process using J-Lok P. When comparing the resin shooter and J-Tech bolt, which uses the traditional resin-bolting process of spinning the bolt through the installed resin capsule and tensioning after a required hold time, the traditional installation process can be completed in times as low as 3 minutes and 20 seconds in good ground conditions. As ground conditions deteriorate, the traditional resin-bolting process becomes inconsistent, slow and frustrating for operators and mining crews. The J-Lok P installation process more than makes up for cycle time improvements in poor ground and provides significant improvements in the following areas:

- Improved development efficiency, installation quality and load transfer.

- Operator confidence.

- Reduced geotechnical risk.

- Guaranteed full encapsulation and homogenous resin mix (this prevents necking of the bolt, a common failure mode from corrosion).

- Installation quality confirmation, as the resin mix and hold times are removed, eliminating operator error or inconsistency with ground condition variation.

As seen in Figure 14, the resin pressure during injection, generally aligns the plate against the nut by packing the underside of plates and totally sealing the installation with resin. This helps to prevent water ingression and atmospheric conditions causing corrosion and necking of the bolt, a common rockbolt corrosion failure mode in many underground mining operations.
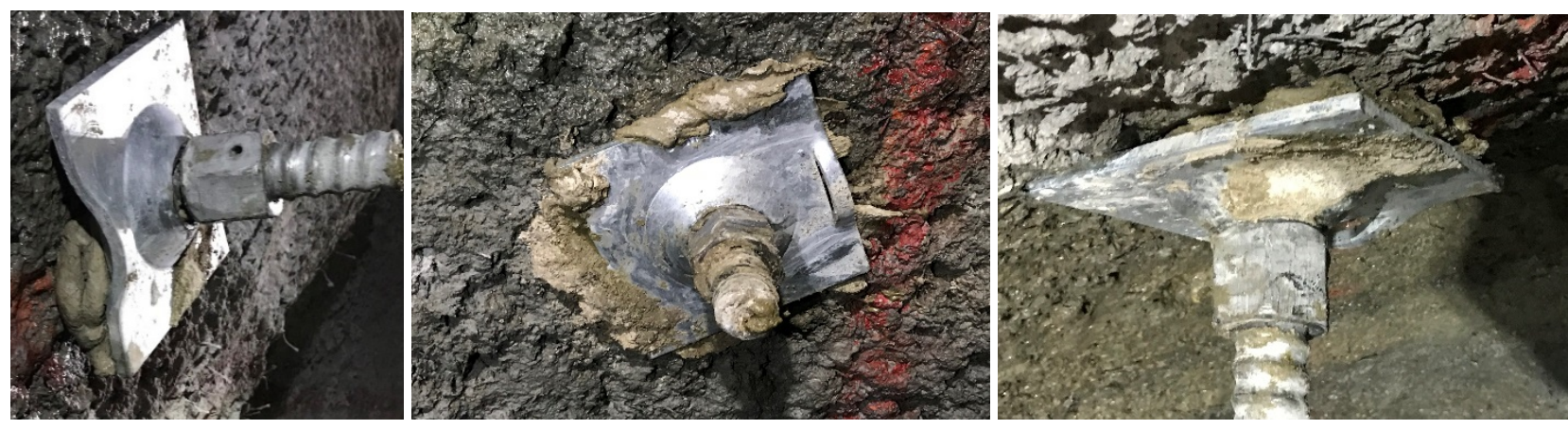

Figure 14 Installation of multiple R32 MPA bolt using the J-Lok P resin injection 
To confirm the resin mixing, a static mixer is inserted into a $2.4 \mathrm{~m}$ length MPA bolt. The method involves inserting the bolt into a $43 \mathrm{~mm}$ inside diameter steel tube and using the J-Lok P system, pumping the bolt and void in the tube with J-Lok P resin. After the resin cures, the tube and bolt are sectioned longitudinally to view resin mixing inside the bolt.

Figure 15 shows sections of the static mixer located inside the MPA bolt. The static mixer is clearly visible with a homogenous resin mix is visible inside and outside the MPA bolt. After the sample was sectioned, the MPA bolt was removed to evaluate resin mixing behind the thread, clearly showing a homogenous resin mix. Further images show the homogenous resin mixed pumped into the MPA bolts. When the bolt is removed after sectioning, definition of the R32 thread clearly remains, providing strong anchorage and protection.
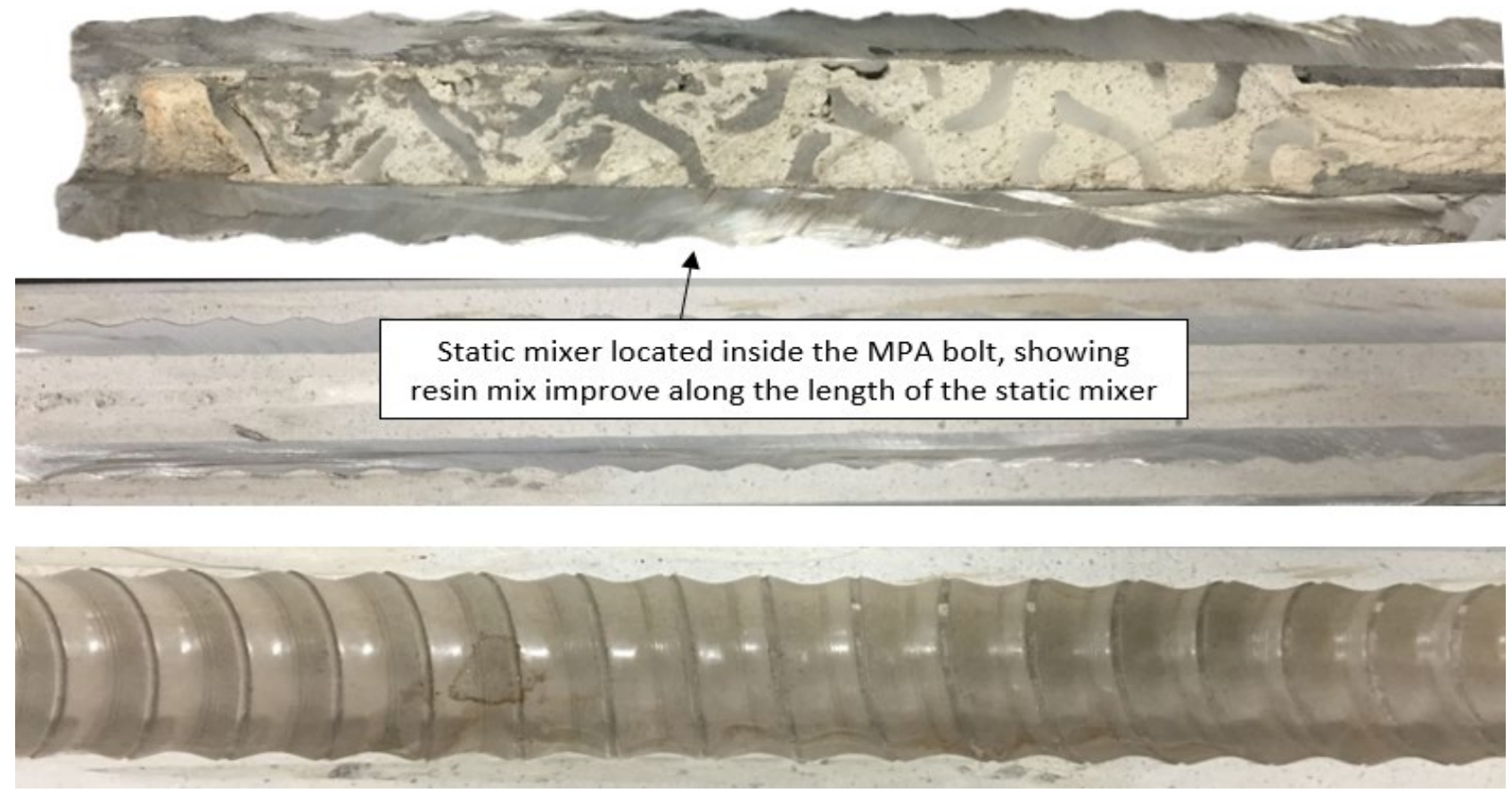

Figure 15 Homogenous J-Lok $\mathrm{P}$ resin mix inside and outside the MPA bolt showing the static resin mixer located inside the MPA bolt

Figure 16 show in-house testing of cable bolt installations using $6 \mathrm{~m} \times 55 \mathrm{~mm}$ tubes. Installation was completed using a skid mounted J-Lok P system and traditional installation methods installed SECTA cables into vertical polymer tubes. Test samples were sectioned to reveal J-Lok $P$ resin pumping inside the cable bulbs revealing installation performance of resin injected cable bolts.
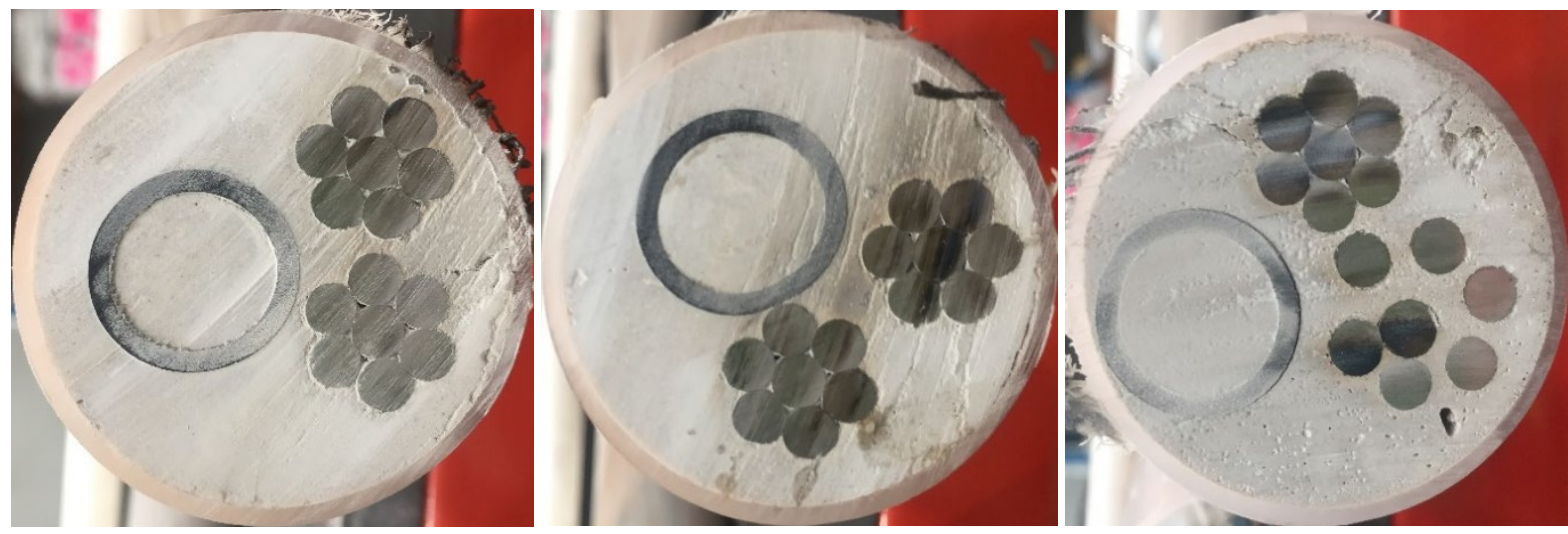

Figure 16 Homogenous J-Lok P resin mix inside and outside the SECTA Cable bolts revealing resin inside cable bulbs and resin grout tube located inside the $55 \mathrm{~mm}$ tube 


\section{Conclusion}

Efforts in developing, installing, testing, validating and achieving the first true, single pass polyester resin-bolting system utilising dynamic ground support elements for hard rock mining applications, has been successfully achieved. With consistent installation performance, which automates the majority of the installation process, the system significantly improves the installed quality of resin bolts and provides Geotechnical Engineers with confidence that ground support is installed as per design.

Traditional bolting practices using resin shooters for small resin capsules and polycarbonate tubes for long resin capsules, are still proven and efficient processes when installed with experienced and proficient operators. It's when ground conditions deteriorate that resin capsule installation become problematic when using traditions resin-bolting practices. This cause's operator frustration, significantly slowing down heading turnover, or in some instances, preventing the heading being resin-bolted which significantly delaying the mining cycle. Similarly, any process completed where outside influences interfere with a planned function, risk is introduced.

Further enhancement of cable bolting systems is proven by eliminating the general 12 hour wait time for grout to cure. Confirmed cable bolt installation, resin injection and cable bolt tensioning to $10 \mathrm{t}$ in 20 minutes is regularly achieved using J-Lok $\mathrm{P}$ resin. This is a significant improvement to development cycle time, especially for single entry mined headings.

The J-Lok P resin injection system has overcome many of the challenges that deep and highly stressed mines encounter. The benefits to the mining cycle, development efficiency, scheduling and planning are critical in achieving targets and most importantly, improving operator safety underground and eliminating risk. The introduction of rock and cable bolts with dynamic capacity installed using traditional installation methods and cable bolting machines provides additional system benefits.

One of the greatest hazards underground is fall of ground. By managing geotechnical risk by ensuring quality installed ground support that exceeds mine design requirements, thus providing a significant contribution to the overall project. The J-Lok P system when used in poor ground, has removed hazards by engineering an installation process which is controlling risks that benefits the underground workforce and planned project schedule.

\section{References}

Faulkner, D, Stankus, J, Ma, K \& Ma, L 2017, Multiple point anchor (MPA), self-drilling, hollow core yielding bolt with injectable J-Lok $P$ resin system for high-stress and squeezing ground conditions, Proceedings of the 51st U.S. Rock Mechanics/Geomechanics Symposium, American Rock Mechanics Association, Alexandria, pp. 533-536.

Watt, G, Roberts, T \& Faulkner, D 2018, 'Single pass drill install and inject self-drilling resin bolt application in poor ground', Proceedings of the Fourth Australasian Ground Control in Mining Conference, The Australasian Institute of Mining and Metallurgy, Melbourne.

De Zoysa, U \& Manoj, H 2018, Dynamic Tested Cement Encapsulated Cablebolt Systems, research report for Oyu Tolgoi LLC, Western Australian School of Mines, Kalgoorlie.

Stankus, J \& Ma, K 2018, Comparison of Pumpable Resin, J-Lok P vs Urea-Silicate white paper, Keystone Mining Services, Pittsburgh. 